\title{
Endoscopic ultrasound-guided diagnosis and man- agement of an unusual gastric submucosal lesion - gastric wall abscess
}

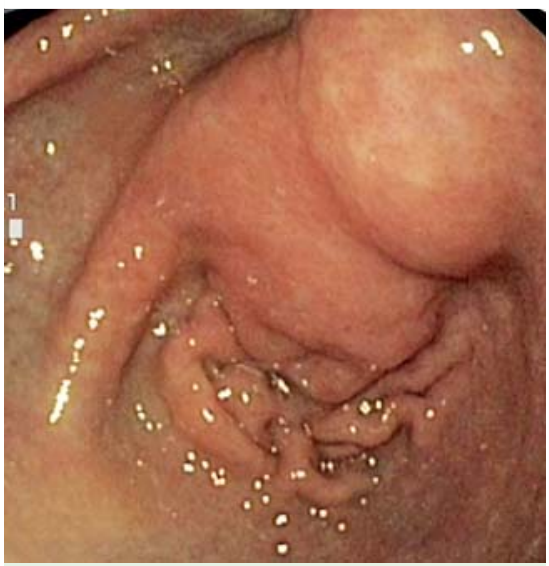

Fig. 1 Submucosal bulge in the gastric antrum in a 65-year-old alcoholic man with upper abdominal pain, early satiety and nausea of 6 weeks' duration.

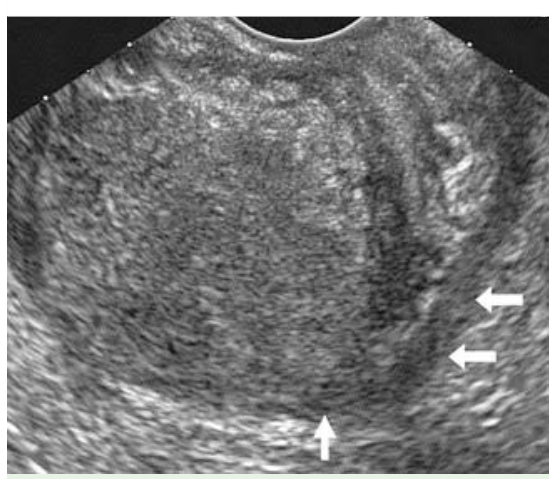

Fig. 3 Endoscopic ultrasound (EUS) showing a submucosal lesion in the antrum. Muscularis propria is seen around the lesion (white arrows).

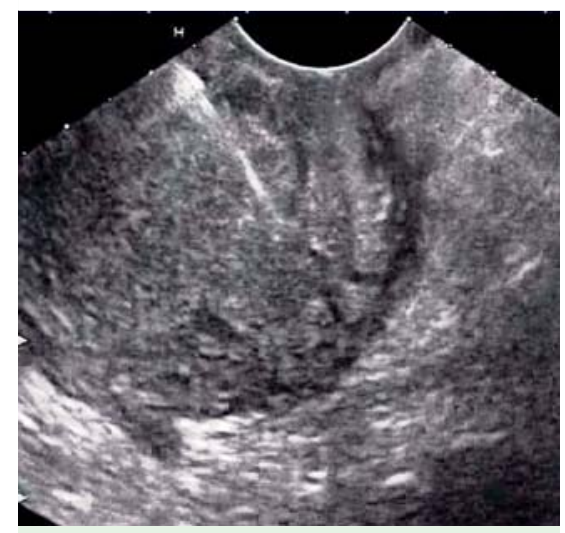

Fig. 4 EUS-guided fine needle aspiration.

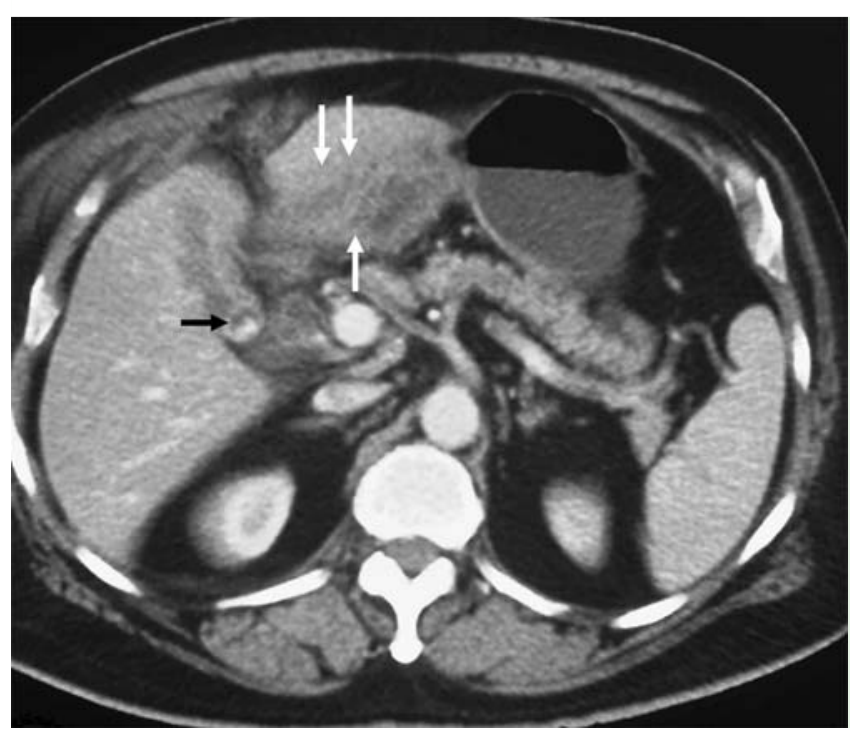

Fig. 2 Contrastenhanced computed tomography (CECT) abdomen showing thickening of the antral wall (white arrows) and gallbladder stone (black arrow).

A 65-year-old alcoholic man presented with upper abdominal pain accompanied by early satiety and nausea of 6 weeks' duration. He had a history of loss of weight and he also had a low-grade fever for the past 7 days. Examination revealed a vague lump in the right upper abdomen. The patient had undergone gastroscopy at the referring center, where a mass in the antrum was reported with inconclusive endoscopic biopsy. We performed a repeat endoscopy, which revealed a submucosal lesion in the antrum ( $\bullet$ Fig. 1 ). Contrast-enhanced computed tomography (CECT) of abdomen showed gallbladder stones with thickening of the antral wall (๑ Fig.2). Endoscopic ultrasound (EUS) revealed a well-defined, heterogeneously echo-textured lesion of $2.5 \mathrm{~cm}$ diameter in the gastric wall ( $\bullet$ Fig.3). EUS-guided fine needle aspiration from the lesion yielded purulent material full of inflammatory cells ( Fig.4). The CECT was reviewed with coronal reconstruction, revealing thickening of the gallbladder wall adjacent to the antrum, and the possibility of a sealed gallbladder perforation was considered ( Fig.5). The patient was treated with intravenous antibiotics and EUSguided drainage of the gastric abscess was done using a nasocystic drain ( $\bullet$ Video 1 ). The patient's condition showed gradual improvement and repeat CECT abdomen revealed resolution of the gastric wall lesion ( Fig. 6 ). After 6 weeks he underwent cholecystectomy, and histopathological examination of the gallbladder revealed features of chronic cholecystitis with deep ulcers and transmural inflammation. The patient's postoperative course was uneventful and he remained asymptomatic over a follow-up of 6 months.

Gastric wall abscess is an unusual and rare infection of the stomach with most cases being diagnosed at laparotomy [1]. EUS is an useful investigation for evaluating intramural lesions [2]. On EUS, gastric wall abscesses are usually seen as a predominantly hypoechoic lesion located mainly in the muscularis propria or the submucosa layer $[1,3]$. However, as there are no specific EUS findings it is difficult to distinguish them from intramural tumors [1]. EUS-guided aspiration can help in arriving at correct diagnosis as in the present case. Surgery along with broadspectrum antibiotics has been the tradi-

\section{Video 1}

EUS-guided transmural drainage of the gastric abscess. Balloon dilation of the transmural tract is being done. 


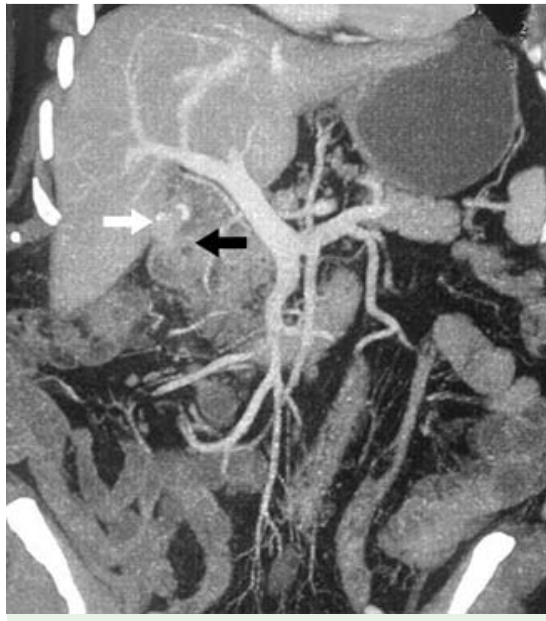

Fig. 5 Reconstructed contrast-enhanced computed tomography (CECT) image shows gallbladder stones (white arrow), the thickened gallbladder wall, and the adjoining gastric wall (black arrow).

tional method of treating gastric wall abscess [4]. Recently, both percutaneous drainage and endoscopic drainage by resecting the mucosa using a snare or a needle-knife, along with a course of antibiotics, have been reported to be successful [1].

Endoscopy_UCTN_Code_CCL_1AF_2AD

Competing interests: None

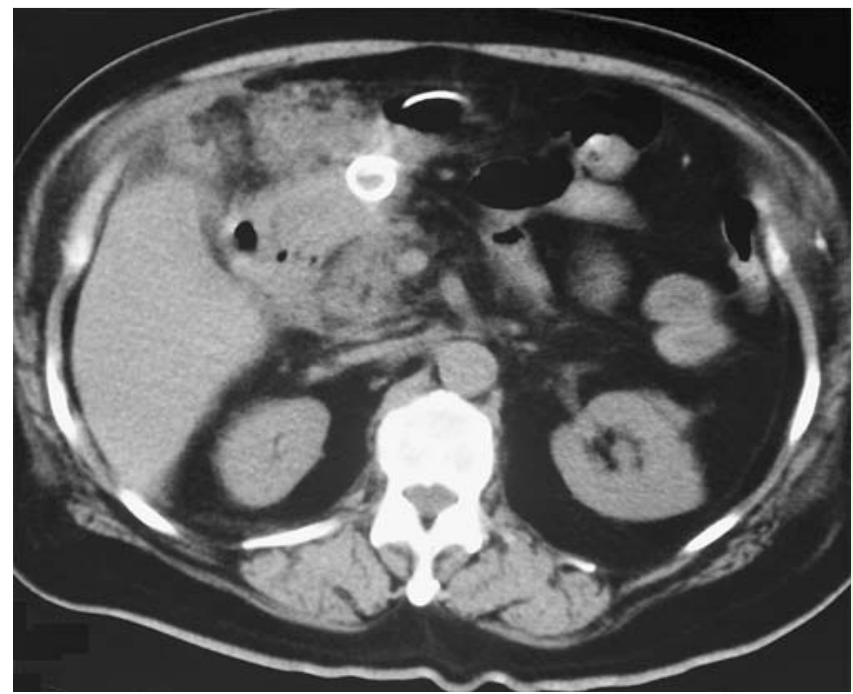

Fig. 6 Post EUS-guided drainage contrastenhanced computed tomography (CECT) view showing pigtail of the nasocystic drain in the abscess cavity.

\section{S. S. Rana ${ }^{1}$, D. K. Bhasin ${ }^{1}$, C. Rao', R. Gupta ${ }^{2}$}

${ }^{1}$ Department of Gastroenterology, Post Graduate Institute of Medical Education and Research (PGIMER), Chandigarh, India

2 Department of Surgery, Post Graduate Institute of Medical Education and Research (PGIMER), Chandigarh, India

\section{References}

1 Yang CW, Yen HH. Endoscopic sonography in the diagnosis and treatment of a gastric wall abscess: a case report and review of the literature. J Clin Ultrasound 2012; 40: 105 108

2 Rana SS, Bhasin DK, Rao C. Gastric outlet obstruction caused by duodenal intramural pseudocyst. Ann Gastroenterol 2013; 26: 71

3 Choong NW, Levy MJ, Rajan E et al. Intramural gastric abscess: case history and review. Gastrointest Endosc 2003; 58: 627
4 Kim GY, Ward J, Henessey B et al. Phlegmonous gastritis: case report and review. Gastrointest Endosc 2005; 61: 168

Bibliography

DOI http://dx.doi.org/

10.1055/s-0032-1326451

Endoscopy 2013; 45: E136-E137

(c) Georg Thieme Verlag KG

Stuttgart · New York

ISSN 0013-726X

\section{Corresponding author \\ Dr S. S. Rana}

Department of Gastroenterology

Post Graduate Institute of Medical Education

and Research (PGIMER)

Chandigarh - 160012

India

Fax: +91-172-2744401

drsurinderrana@yahoo.co.in 